\title{
Retraction Note: TGF- $\beta$ signaling regulates neuronal C1q expression and developmental synaptic refinement
}

\author{
Allison R. Bialas and Beth Stevens
}

Retraction of: Nature Neuroscience https://doi.org/10.1038/nn.3560, published online 27 October 2013.

The corresponding author contacted the journal with concerns regarding the integrity of the data related to this Article. In follow-up experiments, key aspects of the published results that showed evidence that retinal TGF- $\beta$ R2 signaling regulates neuronal C1q expression and developmental synaptic refinement could not be replicated. Most importantly, Figs. $6 \mathrm{~b}$ and 7 , from mice deficient in retinal TGF- $\beta$ receptor $2\left(\mathrm{Tgfbr}^{---}\right)$, were found to contain errors and the results could not be replicated in recent independent follow-up analyses. Moreover, C1q mRNA or protein is not reproducibly upregulated following acute $(6-24 \mathrm{~h})$ treatment of pure retinal ganglion cell (RGC) cultures with astrocyte-conditioned media (Fig 1b,e,f) or TGF- $\beta$ (Fig 2e). Given these findings and other inaccuracies in the Article and Source Data we have since uncovered, the authors wish to retract it. We deeply regret these errors and apologize to our scientific colleagues.

All the authors agree with the retraction.

Published online: 13 January 2022

https://doi.org/10.1038/s41593-021-00877-7

() The Author(s), under exclusive licence to Springer Nature America, Inc. 2022

\section{Retraction Note: From neurons to microglia, with complements}

Noël C. Derecki and Jonathan Kipnis

Retraction of: Nature Neuroscience https://www.nature.com/articles/nn.3579, published online 22 November 2013.

In view of the fact that the article 'TGF- $\beta$ signaling regulates neuronal C1q expression and developmental synaptic refinement', by Allison R. Bialas and Beth Stevens, has been retracted by the authors (https://doi.org/10.1038/s41593-021-00877-7), we retract this News \& Views highlighting the study, because it relied on the validity of the data presented therein.

Published online: 13 January 2022

https://doi.org/10.1038/s41593-021-00892-8

(C) Springer Nature America, Inc. 2022 